\title{
Skill standards and curricula for photonics technicians
}

\section{Dan Hull}

Dan Hull, "Skill standards and curricula for photonics technicians," Proc. SPIE 9663, Eighth International Topical Meeting on Education and Training in Optics and Photonics, 966316 (6 October 2003); doi: 10.1117/12.2207490

SPIE Event: Eighth International Topical Meeting on Education and Training in Optics and Photonics, 2003, Tucson, Arizona, United States 


\title{
Skill Standards and Curricula for Photonics Technicians
}

\author{
Dan Hull \\ President and CEO, CORD, 601 Lake Air Drive, Waco, TX 76710 \\ hull@cord.org
}

\begin{abstract}
Under funding from NSF's ATE program, the national nonprofit R\&D organization CORD recently developed and published the second edition of The National Photonics Skill Standards for Technicians (NPSST), which provides an employer-driven specification for the development of photonics education programs and supporting instructional materials, particularly at the two-year postsecondary level. This paper explains the need for NPSST and overviews its main components-specifications for what photonics technicians should know and be able to do in six broad photonics specialty areas, secondary and postsecondary curriculum outlines, a sample $4+2$ photonics technology course sequence, and foundational knowledge components for two-year photonics technician programs.

(C) 2003 Optical Society of America

OCIS codes: (000.1200) Announcements, awards, news, and organizational activities; (000.2060) Education
\end{abstract}

\section{Introduction}

Over the long haul, U.S. photonics industries face a critical need for more — and more highly skilled — technicians. Even with the recent downturn in the American economy, photonics technicians are in demand, and in future years that demand will significantly outpace growth in the pool of qualified candidates.

To be competitive in the workplace, and to grow as the field changes, photonics technicians need sophisticated technical skills and a strong foundation of academic and employability skills. But they do not necessarily need baccalaureate degrees. The skills required can be obtained through well-designed associate degree programs (especially if foundational programs at feeder high schools provide a "pipeline" for getting students interested in photonics and facilitating the transition to two-year postsecondary education). In fact, surveys show that many employers of technicians prefer graduates of two-year colleges to holders of bachelor's degrees.

For these reasons technical and community colleges provide the ideal mechanisms for producing future generations of photonics technicians. However, for those institutions to provide the highly skilled technicians employers need, industry must collectively provide specifications, i.e., skill standards.

This paper focuses on the recently published second edition of the National Photonics Skill Standards for Technicians (NPSST) (CORD, 2003), which was developed through the National Science Foundation's Advanced Technological Education program. In addition to briefly overviewing the evolution of NPSST, the paper describes the contents of NPSST in such a way that readers - especially employers, but also educators - will become aware of what they can do in their communities to improve dialogue between employers and community colleges, contribute to the development of educational materials and programs, and take other steps necessary to ensure that our nation's photonics industries remain globally competitive long into the future.

A PDF of NPSST can be downloaded from http://utopia.cord.org/STEPII/skills-pdf.htm.

\section{A Challenge to the Photonics Community}

The importance of the role of employers in the activities that NPSST is designed to facilitate cannot be overstated. Without the support of employers and information from them regarding what goes on in the workplace, educators and curriculum developers cannot adequately prepare technicians. At the same time, the participation of employers may require a broadening in their thinking about what constitutes the best possible training for technicians. For a variety of reasons (mainly financial), employers usually support programs that focus narrowly on the skills their organizations need. But one of the premises that NPSST reflects is that those same employers, along with every other stakeholder in the educational enterprise, derive greater benefit, over the long haul, from educational programs that provide foundations - academic as well as technical. When educational programs are too narrowly focused, local job markets may not be able to employ all of their graduates, leaving some young people without employment opportunities that enable them to make optimum use of their training. The skills provided through narrow jobtraining programs also tend to become outdated quickly.

Clearly, taking the long view - in which students are given the tools to grow and adapt over a period of years - is best, for employers and employees alike. 


\section{Background of NPSST}

\subsection{The first edition of NPSST and the STEP Project}

In 1995, CORD released the first edition of NPSST, which represented input from 300 individuals from optics and photonics businesses and industries. The first edition identified the skills and knowledge required of workers and organized that knowledge into a generic program of study that could be emulated by community and technical colleges throughout the United States.

CORD subsequently served as a partner in an NSF ATE-sponsored project called STEP I (Scientific and Technological Education in Photonics), led by Chandra Roychoudhuri of the University of Connecticut. The objectives of that project were to develop ten postsecondary instructional modules based on the standards provided in the first (1995) edition of NPSST.

In 2003, as part of the second phase of the STEP project (STEP II), CORD began the task of producing a new edition of NPSST. Among the goals of the new edition (the focus of this paper) were (1) to make the skill standards consistent with recent developments in the workplace (which had undergone many changes during the six years since the first edition was published), (2) to provide a model for infusing pedagogical innovations and higher levels of academic content (especially math and science) into secondary and postsecondary technical curricula, and (3) to place stronger emphasis on the evaluation of skills (or behaviors) that technicians perform on the job so that the appropriate knowledge could be inferred and identified for educational programs. (The STEP II project is also revising the original curriculum modules; the revised versions will be pilot-tested at community colleges beginning in fall 2003. For more on the STEP II project, see http://utopia.cord.org/STEPII/. Co-PIs for the STEP II project are Arthur Guenther, University of New Mexico; Darrell Hull, CORD; Chandra Roychoudhuri, University of Connecticut; and Fred Seeber, Camden County College.)

\subsection{Development of the New Standards}

Developing the new standards involved several iterative steps that included staff interaction with business/industry representatives - first to ensure the appropriateness of the six specialty areas upon which NPSST is based (see "5. Organization of the Standards in NPSST"), and then to ensure that the scope for each was correct and inclusive to the degree possible. Field validation of the six specialty areas (along with their supporting "critical work functions," tasks, and skills) was conducted via a dedicated, interactive website that enabled respondents to review and critique each critical work function, task, and skill online. Through the assistance of the two largest professional societies in the industry, the SPIE and The Optical Society of America, over 40,000 members of the industry were asked to review the standards and provide input. Of those contacted, over 200 responded. The information provided by the respondents was distilled and forwarded to six industry subcommittees (one for each of the six specialty areas), which reviewed field suggestions. Once input from business and industry members was complete, educators from two-year colleges and technical schools reviewed and validated individual knowledge requirements.

\subsection{Addressing Mathematics Deficiencies}

One of the tasks of the STEP II project is to address the mathematics deficiencies of students who attend two-year colleges. For this purpose, CORD developed a diagnostic instrument that can be used to identify mathematics deficiencies in areas in which students must become proficient to succeed as photonics technicians. CORD also developed a companion math review and study guide designed to help students, especially college freshmen, master the mathematics necessary to perform the exercises, labs, and problems in the introductory optics and photonics curriculum developed through the STEP project. (Both the diagnostic instrument and the review and study guide are available from CORD Communications, Inc. [800-231-3015], which also provides samplers at no cost.)

\section{How NPSST Can Be Used}

NPSST should be used as a guideline for developing and/or updating photonics education programs, especially at the two-year postsecondary level. (The document also provides information pertaining to articulated high school feeder programs.)

NPSST gives users a comprehensive view of what photonics technicians in certain broad specialty areas should know and be able to do - as determined by a consensus of over 200 practicing specialists in the field. Program developers (who should include both educators and employers) will find that the information provided eliminates the need for extensive research and thus gives them a head start on the development process.

NPSST's curriculum resources (see "6. Curriculum Resources in NPSST") are intended as a model, not a prescription for a canned curriculum. But they eliminate $85-90 \%$ of the work that most two-year colleges, working in partnership with local employers, would have to do to create or update their photonics curricula. The specialty 
areas addressed in NPSST provide starting points for almost any program. In many cases, colleges simply need to review and amend the standards to reflect local conditions, then review and amend their curricula accordingly.

The mission of every technical associate degree program should be to (1) provide skills that satisfy the needs of local employers, (2) prepare graduates for further education, and (3) give graduates mobility within the field and the ability to adapt as the field changes. To fulfill that mission, each program should represent a workable balance between the specificity desired by employers and the breadth desired by educators. NPSST is designed to help educators and employers find that balance.

The information provided in NPSST will also help school counselors gain an understanding of the photonics field that will enable them to describe the field's rewards and demands to prospective photonics students.

\section{Organization of the Standards in NPSST}

NPSST divides photonics skill standards into six major specialty areas. The standards pertaining to each area are presented as a series of critical work functions. The description of each critical work function is accompanied by lists of relevant tasks, technical skills, and employability skills.

\subsection{Specialty Areas}

Photonics technicians work in the following six broad areas of specialization (which are the organizing principles upon which NPSST is based).

- Communication: Fiber optics, transmitters, and sensors

- Lighting and illumination: Lighting, displays, and entertainment

- Medicine: Biomedical optics and medical imaging

- Manufacturing: Materials processing, alignment, metrology, and inspection

- Optoelectronics: Nanotechnology, microsystems, and semiconductors

- Imaging and remote sensing: Signal and image processing, environmental, and aerospace

The six specialty areas should not be thought of as airtight categories. Rather, they reflect general groupings of the types of photonics-related activities that take place within a broad cross-section of the optics/photonics industry.

\subsection{Critical Work Functions}

In each of the six specialty areas, technicians are responsible for performing 4-6 critical work functions. Each critical work function is broad and subsumes a number of lower-level tasks. For example, one of the critical work functions for photonics technicians in the specialty area of Communication is:

Assemble various fiber-optic components and modules into subsystems and understand their functions

\subsection{Tasks}

Becoming proficient in each critical work function involves performing one or more of 5-10 tasks. For example, appropriate tasks for the critical "Assembly" work function identified above are:

1. Gather technical requirements for components/devices/materials to facilitate ordering and procurement

2. Assemble components/modules according to manufacturing specifications

3. Prepare component/module for final test

4. Perform reliability test and/or burn-in tests according to manufacturing specifications

5. Integrate fiber-optic components and modules into specified systems

\subsection{Technical and Employability Skills}

Performance of every task requires at least one skill (often several). In NPSST, the term skill refers to the basic abilities necessary to perform a given task. For any task, there may be significant overlap among the required skills. Further, there are two general classifications of skills:

- Technical (example: Measure noise equivalent power)

- Employability (example: Navigate the Internet to gather information)

The importance of employability skills - In 1990, the U.S. Secretary of Labor appointed a commission to identify the skills our young people need for success in the world of work. The purpose of the commission (which came to be known as SCANS, the acronym for Secretary's Commission on Achieving Necessary Skills) was to support the development of a high-skill workforce for a high-performance, high-wage economy. Although the SCANS report (1992) is now over a decade old, its findings and recommendations continue to be a valuable source of information for individuals and organizations involved in education and workforce development, including development of the nation's photonics workforce. 
While the information presented in NPSST pertains primarily to the technical side of the commission's findings, many members of the photonics business and industry community have noted that employability skills are no less important than technical skills (and are generally lacking in the current workforce). Therefore, in NPSST the skills listed for the six photonics areas include both technical and employability skills.

\subsection{Knowledge Components}

In preparation for the compilation of NPSST, educators from two-year colleges provided information that assisted the authors of NPSST in compiling a list of foundational knowledge components based on the tasks and skills requested by employers. Knowledge components are intellectual functions that, in specific combinations, form the basis for understanding concepts in science, engineering, and technology. With respect to NPSST, it can be said that certain knowledge components are essential for behaviors that enable photonics technicians to perform tasks using skills to accomplish critical work functions. For example, an understanding of Snell's law of refraction enables a technician to match a particular light source to a particular fiber. The matching process is a skill, while the underlying principle (Snell's law) is a knowledge component. A good understanding of knowledge components enables technicians to apply principles and techniques to the design, fabrication, modification, and operation of optoelectronic devices and systems.

Some of the knowledge components listed in NPSST will have been learned before students enter two-year postsecondary programs while many will be learned while students are in the programs. In either case, some knowledge components represent core principles that are invariant; that is, they do not change even though the technology and applications based on them do. On the other hand, some knowledge components deal with the operation of a particular optical device such as a Q-switch or a tool such as an optical power meter. In these cases, the knowledge is variant, since its relevance depends on the current state of technology, even though using the device or tool may also require knowledge of invariant laws, principles, or theories.

Comprehending the interplay between invariant knowledge (of laws, principles, and theories) and variant knowledge (of how to use the latest tools and devices) is one of the great challenges facing photonics students - and developers of skill standards such as those contained in NPSST. Yet educational institutions must strive to find the balance between the two if their students are to succeed both in the short and long term, that is, as soon as they exit their programs and throughout their careers as photonics technicians.

\section{Curriculum Resources in NPSST}

\subsection{Overview}

The curriculum materials provided in NPSST reflect a broad view of the educational process, as opposed to focusing exclusively on the two years required for associate degrees. Those two years are critical; for many photonics technicians, they mark the completion of formal education and the period of greatest concentration on the tools of the trade. But they are not likely to produce optimum results unless they are logically coordinated with the four years of high school that precede them.

For this reason, the curriculum recommendations offered in NPSST follow the $4+2$ Tech Prep model. That model, which is supported by most community colleges across the nation, lays out career pathways that enable students to build a strong academic foundation while acquiring technical and employability skills relevant to the career clusters of their choice. The technical focus of the model is general at first and becomes increasingly specific as the student progresses from each grade to the next. The model not only gives high school students a sense of direction but provides the background in mathematics and science that will allow them to attain higher skill and knowledge levels during the first two years of postsecondary education and to pursue further education, if they so choose.

The courses specified in the $4+2$ course sequence provided in Figure 1 are based on the employability and technical skills and on the foundational knowledge components listed in NPSST. The $4+2$ course sequence provides a model educational pathway for students to follow in beginning their photonics studies in high school and, upon graduation, transitioning smoothly to cooperating community or technical colleges. 
Photonics Technology $4+2$ Course Sequence

\begin{tabular}{|c|c|c|c|c|c|c|c|}
\hline & Grade & English & Mathematics & Science & Technology & Technology & Other \\
\hline .气 & 9 & English I & Algebra I & $\begin{array}{c}\text { Biology/ } \\
\text { Life Sciences }\end{array}$ & $\begin{array}{c}\text { Career } \\
\text { Management } \\
\text { Success }\end{array}$ & & \multirow{4}{*}{ 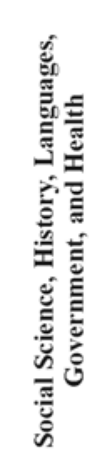 } \\
\hline ప్ & 10 & English II & Geometry & Chemistry & $\begin{array}{c}\text { Computer } \\
\text { Applications }\end{array}$ & & \\
\hline \multirow{2}{*}{ 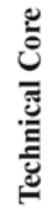 } & 11 & English III & Algebra II & Physics & $\begin{array}{c}\text { DC/AC } \\
\text { Electronics }\end{array}$ & $\begin{array}{l}\text { Introduction } \\
\text { to Photonics }\end{array}$ & \\
\hline & 12 & English IV & Precalculus & $\begin{array}{l}\text { Materials } \\
\text { Science }\end{array}$ & $\begin{array}{c}\text { Digital } \\
\text { Electronics * }\end{array}$ & $\begin{array}{l}\text { Technical } \\
\text { Elective }^{\star \star}\end{array}$ & \\
\hline \multirow{4}{*}{ 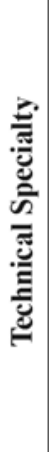 } & $\begin{array}{c}13 \\
\text { 1st Semester }\end{array}$ & English & $\begin{array}{l}\text { Electronic } \\
\text { Circuits for } \\
\text { Photonics }\end{array}$ & $\begin{array}{l}\text { College } \\
\text { Physics }\end{array}$ & $\begin{array}{c}\text { Fundamentals } \\
\text { of Light } \\
\text { and Lasers }\end{array}$ & $\begin{array}{c}\text { Optics and } \\
\text { Optical } \\
\text { Components }\end{array}$ & \multirow{4}{*}{ 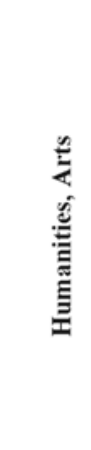 } \\
\hline & $\begin{array}{c}13 \\
\text { 2nd Semester }\end{array}$ & $\begin{array}{c}\text { Technical } \\
\text { Communication }\end{array}$ & $\begin{array}{c}\text { Calculus or } \\
\text { Other Advanced } \\
\text { Math }\end{array}$ & $\begin{array}{l}\text { Advanced } \\
\text { Digital } \\
\text { Electronics }\end{array}$ & $\begin{array}{l}\text { Elements of } \\
\text { Photonics }\end{array}$ & $\begin{array}{c}\text { Optical } \\
\text { Detection and } \\
\text { Measurement }\end{array}$ & \\
\hline & $\begin{array}{c}14 \\
\text { 1st Semester }\end{array}$ & Humanities & $\begin{array}{l}\text { Photonics } \\
\text { Specialty }\end{array}$ & $\begin{array}{l}\text { Technical } \\
\text { Support }\end{array}$ & $\begin{array}{l}\text { Fiber Optics } \\
\text { and Telecom- } \\
\text { munication }\end{array}$ & $\begin{array}{l}\text { Lasers and } \\
\text { Other Light } \\
\text { Sources }\end{array}$ & \\
\hline & $\begin{array}{c}14 \\
\text { 2nd Semester }\end{array}$ & Humanities & $\begin{array}{l}\text { Photonics } \\
\text { Specialty }\end{array}$ & $\begin{array}{l}\text { Technical } \\
\text { Support }\end{array}$ & $\begin{array}{c}\text { Imaging and } \\
\text { Display }\end{array}$ & $\begin{array}{c}\text { Photonics } \\
\text { Applications }\end{array}$ & \\
\hline
\end{tabular}

Fig 1. Photonics technology $4+2$ course sequence

The courses specified in the figure indicate the technical content, scope, and sequence recommended for a broadly-educated photonics technician. (NPSST provides outlines for three high school courses - Career Management Success, Computer/Software Applications, and Introduction to Photonics.) The twelfth-grade course Digital Electronics $(*)$ could be offered for dual (secondary-postsecondary) credit. The technical elective $(* *)$ could be either of the first two college photonics courses, Fundamentals of Light and Lasers or Optics and Optical Components (for which NPSST also provides outlines). The two technical courses marked "Photonics Specialty" provide for specialization in one of the six photonics specialties around which the standards in NPSST have been grouped.

The figure shows how the $4+2$ course sequences divide programs into three two-year layers that systematically increase the student's concentration on his or her career specialty. In the first layer ("foundation," grades 9 and 10) students study "contextual" academics (math, science, language arts, other), begin career exploration, learn employability skills, and learn to apply technology skills to their fields of interest. In the second layer ("technical core," grades 11 and 12) students study increasingly advanced contextual academics, acquire knowledge and skills for the technical core of the fields they plan to pursue, and participate in work-based learning experiences such as job shadowing and summer internships. Twelfth graders usually take at least one dual-credit postsecondary course. In the third layer ("technical specialty," postsecondary years 1 and 2) students focus on their career areas in-depth but are encouraged to continue work in academic fields and the humanities. Students who complete this layer are qualified for employment in their areas of specialization or, if they so choose, admission to baccalaureate degree programs.

\subsection{STEP II Courses (Postsecondary)}

NPSST provides outlines for the following eight postsecondary courses.

1. Fundamentals of Light and Lasers

2. Elements of Photonics

3. Optics and Optical Components 
4. Lasers and Other Light Sources

5. Detection and Measurement

6. Fiber Optics and Communication

7. Imaging and Display

8. Photonics Applications

The outlines are laid out in sequenced modules that identify the information that should be covered in each course and suggest an order of presentation that will enable students to synthesize new information by building on information covered in previous modules.

The outlines reflect an attempt through the combined efforts of two-year postsecondary educators, industry representatives, and the authors to achieve an optimum balance between variant and invariant knowledge. The outlines are modular, which means, among other things, that some material is presented more than once, though each time from a different perspective. This is to be expected in a situation in which the acquisition of variant knowledge depends on having already acquired certain invariant knowledge.

\section{Future Plans}

The larger picture for STEP involves the completion of STEP II and a final three-year phase for further curriculum development and implementation called STEP III. In STEP II, the project will complete a thorough revision of instructional modules developed under STEP I. The revised modules will be piloted beginning in fall 2003. The next two challenges for the project are creation of additional modules and preparation of teachers to teach the modules.

NPSST calls for 54 instructional modules. Under STEP II, the NSF has provided funding for development of seven modules beyond the eleven that already exist. The goal of the project's principal investigators is to identify business and industry sponsors for another seven modules. The hope is that for each of those seven modules, an industry sponsor would provide (1) the $\$ 25,000$ necessary for development, (2) examples of equipment or materials that may be used for instructional purposes in the module, and (3) technical assistance for the author as needed.

Faculty preparation for STEP II is to be handled using a three-pronged approach. First, online courses will be used to assist faculty who have technical backgrounds but no expertise in optics or photonics technology. The intent is to develop single courses in introductory optics/photonics at schools that have never offered the topic before; the courses would be offered as electives for other technology programs. Second, the project will provide two half-day short courses that introduce experienced faculty to the curriculum. Finally, the project will support a capstone symposium with faculty who have used the curriculum material during the pilot program to allow them to discuss with their peers their experiences in using the STEP curriculum.

\section{Conclusion}

Development of NPSST is the first critical task of the STEP II project. The goals of the STEP II project continue to build on that critical first step, as well as the foundation laid by the STEP I project. Those goals are (1) development of up-to-date photonics curriculum materials; (2) promotion, dissemination, and facilitation of the use of project materials at community and technical colleges; and (3) demonstration of how articulated curricula, beginning in the ninth grade and continuing through the baccalaureate degree, enhance the value of associate degrees in photonics by making the transition from high school to two-year colleges seamless and by providing options for education beyond the associate degree. Achievement of these goals will require further assistance from business and industry in the development of additional curriculum, and support for STEP III in the coming years.

NPSST is available, without charge, to any organization, employer, and/or educational institution. Local partnerships or employers and educators are encouraged to study the document and use it as a guide for improving, updating, and initiating photonics programs at two-year colleges in their areas. CORD staff members are available to provide assistance if needed. 